Hydrol. Earth Syst. Sci., 17, 2147-2159, 2013

www.hydrol-earth-syst-sci.net/17/2147/2013/

doi:10.5194/hess-17-2147-2013

(C) Author(s) 2013. CC Attribution 3.0 License.

\title{
Errors in climate model daily precipitation and temperature output: time invariance and implications for bias correction
}

\author{
E. P. Maurer ${ }^{1}$, T. Das ${ }^{2}$, and D. R. Cayan ${ }^{3}$ \\ ${ }^{1}$ Civil Engineering Dept., Santa Clara University, Santa Clara, CA, USA \\ ${ }^{2} \mathrm{CH} 2 \mathrm{MHill}, 402 \mathrm{~W}$. Broadway, San Diego, CA, USA \\ ${ }^{3}$ Division of Climate, Atmospheric Sciences, and Physical Oceanography, Scripps Institution of Oceanography \\ and Water Resources Division, US Geological Survey, La Jolla, CA, USA
}

Correspondence to: E. P. Maurer (emaurer@engr.scu.edu)

Received: 21 December 2012 - Published in Hydrol. Earth Syst. Sci. Discuss.: 1 February 2013

Revised: 7 May 2013 - Accepted: 12 May 2013 - Published: 7 June 2013

\begin{abstract}
When correcting for biases in general circulation model (GCM) output, for example when statistically downscaling for regional and local impacts studies, a common assumption is that the GCM biases can be characterized by comparing model simulations and observations for a historical period. We demonstrate some complications in this assumption, with GCM biases varying between mean and extreme values and for different sets of historical years. Daily precipitation and maximum and minimum temperature from late 20th century simulations by four GCMs over the United States were compared to gridded observations. Using random years from the historical record we select a "base" set and a $10 \mathrm{yr}$ independent "projected" set. We compare differences in biases between these sets at median and extreme percentiles. On average a base set with as few as 4 randomly-selected years is often adequate to characterize the biases in daily GCM precipitation and temperature, at both median and extreme values; $12 \mathrm{yr}$ provided higher confidence that bias correction would be successful. This suggests that some of the GCM bias is time invariant. When characterizing bias with a set of consecutive years, the set must be long enough to accommodate regional low frequency variability, since the bias also exhibits this variability. Newer climate models included in the Intergovernmental Panel on Climate Change fifth assessment will allow extending this study for a longer observational period and to finer scales.
\end{abstract}

\section{Introduction}

The prospect of continued and intensifying climate change has motivated the assessment of impacts at the local to regional scale, which entails the prerequisite use of downscaling methods to translate large-scale general circulation model (GCM) output to a regionally relevant scale (Carter et al., 2007; Christensen et al., 2007). This downscaling is typically categorized into two types: dynamical, using a higher resolution climate model that better represents the finer-scale processes and terrain in the region of interest; and statistical, where relationships are developed between large-scale climate statistics and those at a fine scale (Fowler et al., 2007). While dynamical downscaling has the advantage of producing complete, physically consistent fields, its computational demands preclude its common use when using multiple GCMs in a climate change impact assessment. We thus focus our attention on statistical downscaling, and more specifically on the bias correction inherently included in it.

With the development of coordinated GCM output, with standardized experiments, formats, and archiving (Meehl et al., 2007), impact assessments can more readily use an ensemble of output from multiple GCMs. This allows the separation of various sources of uncertainties and the assessment to some degree of the uncertainty due to GCM representation of climate sensitivity (Hawkins and Sutton, 2009; Knutti et al., 2008; Wehner, 2010). In combining a selection of GCMs to form an ensemble, the inherent errors in each GCM must be accommodated. In the ideal case, if all GCM biases were stationary in time (and with projected trends in the future), 
removing the bias during an observed period and applying the same bias correction into the future should produce a projection into the future with lower bias as well. Ultimately this would place all GCM projections on a more or less equal footing.

Some past studies support the assumption of timeinvariant GCM biases in bias correction schemes. For example, Macadam et al. (2010), who demonstrate that using GCM abilities to reproduce near-surface temperature anomalies (where biases in mean state are removed) was found to produce inconsistent rankings (from best to worst) of GCMs for different $20 \mathrm{yr}$ periods in the 20th century. However, Macadam et al. (2010) found when actual temperatures were used to assess model performance, a more stable GCM ranking was produced. While studying regional climate model biases, Christensen et al. (2008) found systematic biases in precipitation and temperature related to observed mean values, although the biases between different subsets of years increased when they differed in temperature by $4-6{ }^{\circ} \mathrm{C}$.

Biases in GCM output have been attributed to various climate model deficiencies such as the coarse representation of terrain (Masson and Knutti, 2011), cloud and convective precipitation parameterization (Sun et al., 2006), surface albedo feedback (Randall et al., 2007), and representation of landatmosphere interactions (Haerter et al., 2011) for example. Some of these deficiencies, as persistent model characteristics, would be expected to result in biases in the GCM output that are similar during different historical periods and into the future. For example, errors in GCM simulations of temperature occur in regions of sharp elevation changes that are not captured by the coarse GCM spatial scale (Randall et al., 2007); these errors would be expected to be evident to some degree in model simulations for any time period. However, as Haerter et al. (2011) state “... bias correction cannot correct for incorrect representations of dynamical and/or physical processes ...", which points toward the issue of some GCM deficiencies producing different biases in land surface variables as the climate warms, generically referred to as timeand state-dependent biases (Buser et al., 2009; Ehret et al., 2012). For example, Hall et al. (2008) show that biases in the representation of spring snow albedo feedback in a GCM can modify the summer temperature change sensitivity. This implies that as global temperatures climb in future decades, some biases could be amplified by this feedback process. While we do not assess the sources of GCM biases explicitly, we aim to examine where different GCMs exhibit similar precipitation and temperature biases between two sets of independent years, which may carry implications as to which sources of error are important in different regions.

Many of the prior assessments of GCM bias have been based on GCM simulations of monthly, seasonal, or annual mean quantities. Recognizing the important role of extreme events in the projected impacts of climate change (Christensen et al., 2007), statistical downscaling of daily GCM output can been used to provide information on the projected changes in regional extremes (e.g., Bürger et al., 2012; Fowler et al., 2007; Tryhorn and DeGaetano, 2011). While accounting for biases at longer timescales, such as monthly, can reduce the bias in daily GCM output, the daily variability of GCM output may have biases (such as excessive drizzle; e.g., Piani et al., 2010) that cannot be addressed by a correction at longer timescales. By addressing biases at the daily scale, we can assess the ability to correct for biases at a timescale appropriate for many extreme events (Frich et al., 2002).

Biases in daily GCM output can be removed in many ways. At its simplest, the perturbation, or "delta" method shifts the observed mean by the GCM simulated mean change, effectively accounting for GCM mean bias only (Hewitson, 2003), which is useful but has its limitations (Ballester et al., 2010). Separate perturbations can be applied to different magnitude events (e.g., Vicuna et al., 2010) to capture some of the potentially asymmetric biases in different portions of the observed probability distribution function. In its limit, perturbations can be applied along a continuous distribution, resulting in a quantile mapping technique (Maraun et al., 2010; Panofsky and Brier, 1968). This type of approach has been applied in a variety of formulations for bias correcting monthly and daily climate model outputs (e.g., Abatzoglou and Brown, 2012; Boé et al., 2007; Ines and Hansen, 2006; Li et al., 2010; Piani et al., 2010; Themeß1 et al., 2012; Thrasher et al., 2012), and has been shown to compare favorably to other statistical bias correction methods (Lafon et al., 2012). Regardless of the approach, all of these methods of bias removal assume that biases relative to historic observations will be the same during the projections.

For this study, we examine the biases in daily GCM output over the conterminous United States. We address the following questions: (1) are the daily biases the same between median and extreme values? (2) Are biases the same over different randomly selected sets of years (i.e., time invariant)? We address these using daily output from four GCMs for precipitation, and maximum and minimum daily temperature. We consider biases at both median and extreme values because, as attention focuses on extreme events such as heat waves, peak energy demand, and floods, the assumptions in bias correction of daily data at these extremes becomes at least as important as at mean conditions.

\section{Methods and data}

The domain used for this study is the conterminous United States, as represented by 20 individual $2^{\circ}$ by $2^{\circ}$ (latitude/longitude) grid boxes, shown in Fig. 1. For the period 1950-1999, daily precipitation, maximum and minimum temperature output were obtained from simulations of four GCMs listed in Table 1. These four GCM runs were those selected for a wider project aimed at comparing different statistical and dynamical downscaling techniques 
Table 1. GCM names and runs used in this study.

\begin{tabular}{llll}
\hline Modeling Group & GCM Name & Model Runs & Primary Reference \\
\hline Centre National de Recherches Meteorologiques, France & CNRM & CNRM CM3: 20c3m run 1 & Salas-Mélia et al. (2005) \\
Geophysical Fluid Dynamics Laboratory, USA & GFDL & GFDL 2.1: 20c3m run 1 & Delworth et al. (2006) \\
National Center for Atmospheric Research, USA & PCM & NCAR PCM1: 20c3m run 2 & Washington et al. (2000) \\
National Center for Atmospheric Research, USA & CCSM & NCAR CCSM3: 20c3m run 5 & Kiehl et al. (1998) \\
\hline
\end{tabular}

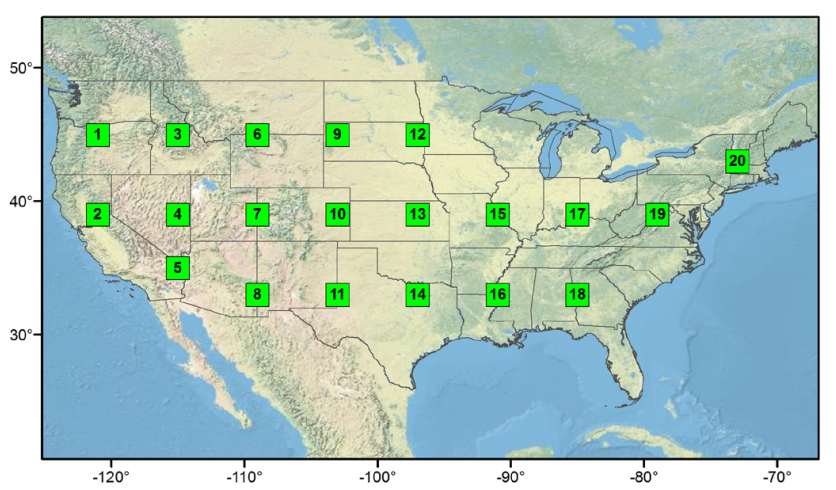

Fig. 1. Location of the 20 grid cells used in this analysis.

in California and the Western United States (Pierce et al., 2013). All GCMs were regridded onto a common 2-degree grid to allow direct comparisons of model output. While this coarse resolution inevitably results in a reduction of daily extremes that would be experienced at smaller scales due to effects of spatial averaging (Yevjevich, 1972), GCM-scale daily extremes are widely used to characterize projected future changes in important measures of impacts (Tebaldi et al., 2006).

As an observational baseline the 1/8 degree Maurer et al. (2002) data set for the 1950-1999 period was used, which was aggregated to the same 2-degree spatial resolution as the GCMs. This data set consists of gridded daily cooperative observer station observations, with precipitation rescaled (using a multiplicative factor) to match the 1961-1990 monthly means of the widely-used PRISM data set (Daly et al., 1994), which incorporates additional data sources for more complete coverage. This data set has been extensively validated, and has been shown to produce high quality streamflow simulations (Maurer et al., 2002). This data set was spatially averaged, by averaging all $1 / 8$ degree grid cells within each of the 2-degree GCM-scale grid boxes, which represent approximately $40000 \mathrm{~km}^{2}$. While GCM biases have been shown to have some sensitivity to the data set used as the observational benchmark (Masson and Knutti, 2011), the relatively high density station observations (averaging one station per 700 $1000 \mathrm{~km}^{2}$ (Maurer et al., 2002), much more than an order of magnitude smaller than the area of the 2-degree GCM cells) in the observational data set provides a reasonable baseline against which to assess GCM biases, especially when aggregated to the GCM scale.

To assess the variability of biases with time, the historical record was first divided into two pools: one of even years and the other of odd years. From each of these pools, years were randomly selected (without replacement) from the historical record: (1) a "base" set (between 2 and $20 \mathrm{yr}$ in size) randomly selected from the even-year pool; (2) a "projected" set of 10 randomly-selected years drawn from the odd-year pool. As in Piani et al. (2010), a decade for the projected set size provides a compromise between the preference for as long a period as possible to characterize climate and the need for non-overlapping periods in a $50 \mathrm{yr}$ observational record. In addition, the motivation for fixing a relatively short $10 \mathrm{yr}$ set size derives from this study being connected to that of Pierce et al. (2013). In the Pierce et al. (2013) study the challenge was to bias correct climate model simulations consisting of a single decade in the 20th century and another decade of future projection, and the question arose as to whether the base period was of adequate size for bias correction. While longer climatological periods are favorable and more typical for characterizing climate model biases (e.g., Wood et al., 2004), recent research suggests that in some cases periods as short as a decade may suffice, adding only a minor source of additional uncertainty (Chen et al., 2011).

The same sets of years were used from both the GCM output and the observed data. There is no reason for year-to-year correspondence between the GCM output and the historical record as reflected in the observations, since GCM simulations are only one possible realization for the time period. However, the longer-term climate represented by many years should be comparable, and it is the aggregate statistics of all years in the sample that are assessed. For each of these sets, cumulative distribution functions (CDFs) were prepared by taking all of the days in a season: summer, June-August (JJA) for maximum daily temperature (Tmax); or winter, December-February (DJF) for precipitation (Pr) and minimum daily temperature (Tmin). The use of a single season for each variable is for the purpose of capturing summer and winter extreme values for temperature, and cold season precipitation extremes, which are of particular importance in the Western United States where winter precipitation dominates the hydroclimatic characteristics (Pyke, 1972). We recognize the importance of other seasonal variables for different regions of the domain, especially related to precipitation (e.g., 
Karl et al., 2009), but reserve a more comprehensive effort for future research. Within each season, two percentiles are selected for analysis: the median and the 95th percentile for Pr and Tmax, and the median and 5th percentile for Tmin.

A Monte Carlo experiment was performed by repeating 100 times the random selection of "base" sets and $10 \mathrm{yr}$ "projected" sets. This number of simulations was chosen to provide adequate (so that repeated computations produced comparable results) sampling for all selections of sets of years without approaching the maximum number of combinations for the most limiting case, that is, 300 possible combinations of $2 \mathrm{yr}$ selected from a pool of $25 \mathrm{yr}$. Also, a second set of 100 Monte Carlo simulations was performed, which produced indistinguishable results, showing this number of simulations is adequate for producing consistent results. For each of the base and projected sets, the constructed CDFs were used to determine the 50th and 95th (Tmax and Pr) or 5th and 50th (Tmin) percentiles for both observations and GCM output. The GCM biases relative to observations were calculated, composing two arrays of 100 values at each percentile.

At each percentile and for each Monte Carlo simulation, the samples are compared using the following $R$ index:

$R=\frac{\left|B_{\mathrm{P}}-B_{\mathrm{B}}\right|}{\left(\left|B_{\mathrm{P}}\right|+\left|B_{\mathrm{B}}\right|\right) / 2}$

where $B$ is the bias, the difference between the GCM value and the observed value, and the subscripts "P" and "B" indicate the projected and base sets, respectively; the vertical bars are the absolute value operator. What this index represents is the ratio of the difference in bias between the base and projected sets and the average bias of the base and projected sets. A value of $R$ greater than one indicates a larger difference in bias between the two sets than the average bias of the GCM, meaning a higher likelihood that bias correction would degrade the GCM output rather than improve it. $R$ has a range of $0 \leq R \leq 2$. This index is similar to that used by Maraun (2012) to characterize the effectiveness of bias correction of temperatures produced by regional climate models. The principal difference in the $R$ index to that of Maraun (2012) is that the $R$ index is normalized by an estimate of the mean bias; since in this case both the base and projected sets are selected from the historical record, the mean of the two bias estimates (for the base and projected sets) is used to estimate the average bias. The above procedure is repeated at each of the 20 selected grid cells and for the four GCMs included in this analysis.

As an alternative, the mean bias in the denominator could be estimated differently, such as using only the base period bias $B_{\mathrm{B}}$. The advantage of using the $R$ formulation above is that it is insensitive to which set is designated as "projected" and which is "base". For example, $B_{\mathrm{B}}=4, B_{\mathrm{P}}=2$ and $B_{\mathrm{B}}=2, B_{\mathrm{P}}=4$ produce the same $R$ value, but would not if only $B_{\mathrm{B}}$ or $B_{\mathrm{P}}$ were used in the denominator. This provides the additional advantage that, since both the base and projected sets are randomly drawn from the historical record
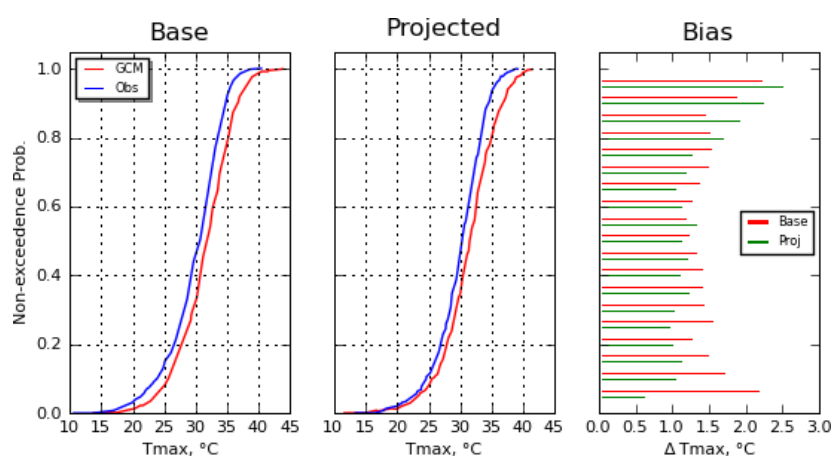

Fig. 2. Comparison of cumulative distribution functions of daily summer (JJA) maximum temperature between a GCM (NCAR CCSM3 in this case) and observations for a single grid point at $39^{\circ} \mathrm{N}, 121^{\circ} \mathrm{W}$ (cell 2 in Fig. 1). Base set is a $20 \mathrm{yr}$ random sample from 1950-1999 (left panel); projected is a different $10 \mathrm{yr}$ random sample from the same period (center panel), and bias (right panel) is calculated at 19 evenly spaced quantiles $(0.05,0.10, \ldots, 0.95)$.

and since the $R$ index is insensitive to this designation, results for varying base set sizes with a fixed projected set size would be the same as those for varying projected set sizes and a fixed base set size.

\section{Results and discussion}

Examples of CDFs for JJA Tmax for a single grid cell for the NCAR CCSM3 GCM are illustrated in Fig. 2. For a random $20 \mathrm{yr}$ base set (left panel) the GCM overestimates Tmax (relative to observations) at all quantiles, and the bias appears similar for low and high extreme values. For the $10 \mathrm{yr}$ projected set (center panel), the bias appears similar to the base set, with the GCM overestimating Tmax at all quantiles. However, the bias (right panel), calculated at 19 evenly spaced quantiles $(0.05,0.10, \ldots, 0.95)$ shows asymmetry across the quantiles. Especially noticeable is that at low quantiles, representing extreme low Tmax values, the bias for the base set is more than $1{ }^{\circ} \mathrm{C}$ greater than for the projected set, while at median values the base and projected set biases are closer. While this represents just one random base and projected set, it illustrates some of the potential complications in assuming biases are systematic in GCM simulations.

For each of 100 Monte Carlo simulations, biases relative to observations for the base and projected sets are calculated, as is the difference between the bias for the base and projected sets, and finally the $R$ index. The results across the domain for daily JJA Tmax are illustrated in Figs. 3-5 for the GFDL model output.

Figure 3 shows that the mean (of the 100 Monte Carlo simulations) JJA Tmax GFDL model biases (left panels) vary across the domain. These vary from large negative values (a cool bias) in the northern Rocky Mountain region and 
a warm bias throughout the central plains, especially at the high extreme (95th percentile), well known characteristics of this version of the model (Klein et al., 2006). The magnitude of the GCM bias at specific grid cells in Fig. 3 (left panels) shows consistency for any sample of years from the late 20th century, demonstrating that there is some spatial and temporal consistency in the GCM bias. This supports the concept of model deficiencies in representing detailed terrain and regional processes playing a role in creating the biases. Rather than the magnitude of the biases, the focus here is on determining whether at each point across the domain these biases are the same between two different randomly selected sets of years.

Figure 3 also shows that the mean differences between the two sets (base and projected) of biases in GCM Tmax for both the 50th and 95th percentiles (center panels) are generally smaller than the GCM bias (left panels). This is reflected in most of the $R$ values (right panels) having a mean below one, with the worst case being with the smallest base set sample $(4 \mathrm{yr})$ for the extreme 95 th percentile Tmax statistic. Also of note in Fig. 3 is that there is a decline in the number of grid cells where $R$ exceeds one between the 4 and 12 yr base set size, while little difference is evident between the 12 and $20 \mathrm{yr}$ base set size. This suggests that, for daily simulations of JJA Tmax, a $12 \mathrm{yr}$ base set works nearly as well as a $20 \mathrm{yr}$ base set for characterizing GCM biases, both for median and extreme values, and that there is a diminishing return for using larger base sets for characterizing bias. The potential for using base sets of different sizes is discussed in greater detail below.

Figure 4 shows the bias and changes in bias for Tmin for the GFDL model. Of note is that the locations of high and low biases in Tmin, as with Tmax, occur in the same regions for any base set size, again supporting the concept of a timeinvariant, geographically based model deficiency underlying at least a portion of the bias. It is interesting to observe in Fig. 4 that the location of greatest bias, the grid cells with the greatest change in bias, and the points with $R$ exceeding one, are all different from Fig. 3. This suggests that the factors driving biases in Tmin are distinct from those affecting Tmax, though it is beyond the scope of this effort to determine the sources of the biases in GCM output. In addition, the $R$ index values in Fig. 4 are generally larger than in Fig. 3, with more grid cells exceeding a mean value of one for both the median and extreme at all base set sizes. This indicates that there are more grid cells in the domain where Tmin biases are time dependent than for Tmax for this GCM.

Figure 5 shows the GFDL model bias for winter precipitation. The left column of the biases in median and extreme daily precipitation shows one distinct pattern not as evident as in the figures of Tmax and Tmin. In particular, the biases are substantially larger for the extremes, consistent with the broad interpretation of Randall et al. (2007) that temperature extremes are simulated with greater success by GCMs than precipitation extremes. As evident for Tmin (Fig. 4) the
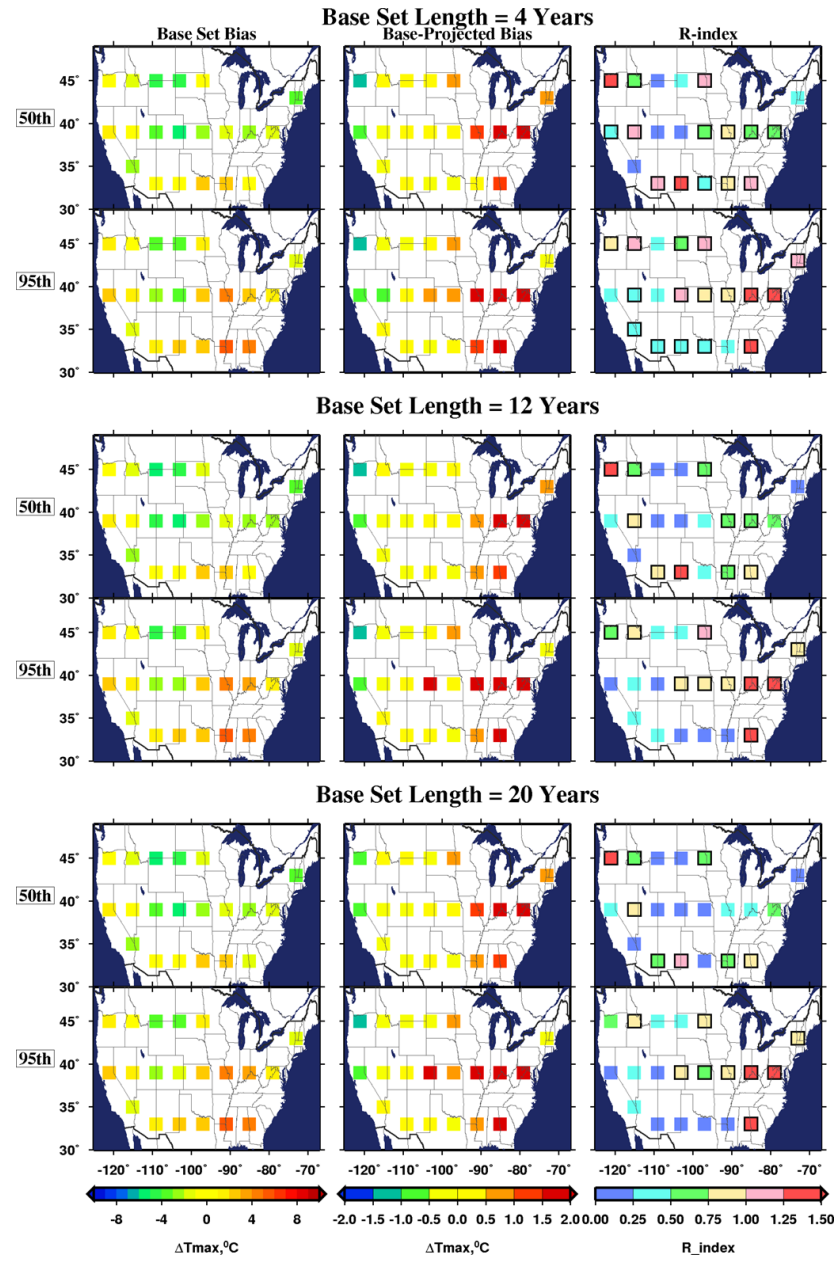

Fig. 3. Mean bias (of 100 Monte Carlo simulations) in daily JJA Tmax for the GFDL model output for three different base set sizes (left panels), the mean difference in bias between the base and projected sets (center panels), and the mean $R$ index value (right panels). Grid cells with dark outlines indicate where $R$ values are not consistently less than 1 at $95 \%$ confidence. Projected set size is $10 \mathrm{yr}$.

number of occurrences of mean $R<1$ in Fig. 5 (summarized in Table 2) is fairly consistent between all base set sizes. This indicates that, in the mean, a short base set of 4 randomlyselected years provides nearly as good a representation of the systematic GCM biases as a $20 \mathrm{yr}$ set. The number of occurrences where the 95th percentile $R$ (estimated as the 95th largest value of the 100 Monte Carlo samples) exceeds 1 drops sharply between a 4 and $12 \mathrm{yr}$ base period. This indicates that, in the mean, a short base set of $4 \mathrm{yr}$ provides nearly as good a representation of the systematic GCM biases as a $20 \mathrm{yr}$ set. For a $95 \%$ confidence threshold, however, a longer base set of $12 \mathrm{yr}$ provides improvement in bias correction results. 
Table 2. Number of grid cells (out of the 20 in the domain) with mean (of 100 Monte Carlo simulations) $R>1$ and, in parentheses, the number of occurrences where the 95th percentile of $R$ exceeds 1, for three base set sizes and two percentiles.

\begin{tabular}{|c|c|c|c|c|c|c|}
\hline \multirow[b]{2}{*}{ GCM } & \multicolumn{2}{|c|}{ Tmax } & \multicolumn{2}{|c|}{ Tmin } & \multicolumn{2}{|c|}{$\operatorname{Pr}$} \\
\hline & Median & Extreme & Median & Extreme & Median & Extreme \\
\hline \multirow[t]{3}{*}{ CNRM } & 4 yr: 2(5) & 4 yr: $2(5)$ & 4 yr: 6(15)) & 4 yr: 7(10) & 4 yr: 7(15) & 4 yr: 8(13) \\
\hline & 12 yr: $1(3)$ & 12 yr: $2(5)$ & 12yr: 5(10) & 12 yr: $7(10)$ & 12 yr: $6(11)$ & 12 yr: $8(13)$ \\
\hline & 20 yr: $1(3)$ & 20 yr: $2(5)$ & 20 yr: $5(8)$ & 20 yr: $7(10)$ & 20 yr: $5(10)$ & 20 yr: $8(13)$ \\
\hline \multirow[t]{3}{*}{ GFDL } & 4 yr: 6(14) & 4 yr: 3(9) & 4 yr: $9(18)$ & 4 yr: 5(10) & 4 yr: 3(14) & 4 yr: 4(8) \\
\hline & 12 yr: 2(10) & 12 yr: 3(9) & 12 yr: $6(14)$ & 12 yr: $5(10)$ & 12 yr: 3(9) & 12 yr: $4(8)$ \\
\hline & 20 yr: 2(8) & 20 yr: 3(9) & 20 yr: $5(12)$ & 20 yr: 5(10) & 20 yr: 3(7) & 20 yr: 4(8) \\
\hline \multirow[t]{3}{*}{ PCM } & 4 yr: 4(8) & 4 yr: 5(11) & 4 yr: 6(16) & 4 yr: 6(12) & 4 yr: 6(11) & 4 yr: 6(16) \\
\hline & 12 yr: $5(6)$ & 12 yr: $4(9)$ & 12 yr: $5(9)$ & 12 yr: $3(7)$ & 12 yr: $2(7)$ & 12 yr: $5(10)$ \\
\hline & 20 yr: 5(6) & 20 yr: 3(8) & 20 yr: 4(9) & 20 yr: 2(7) & 20 yr: 2(7) & 20 yr: $5(10)$ \\
\hline \multirow[t]{3}{*}{ CCSM } & 4 yr: 5(12) & $4 \mathrm{yr}: 2(3)$ & 4 yr: 3(14) & 4 yr: 11(18) & 4 yr: $6(11)$ & 4 yr: 3(9) \\
\hline & 12 yr: $4(8)$ & 12 yr: $2(3)$ & $12 \mathrm{yr}: 3(6)$ & 12 yr: $11(18)$ & $12 \mathrm{yr}: 4(10)$ & 12 yr: 3(9) \\
\hline & 20 yr: 4(8) & 20 yr: 2(3) & 20 yr: 2(5) & 20 yr: 11(18) & 20 yr: $3(8)$ & 20 yr: 3(9) \\
\hline
\end{tabular}

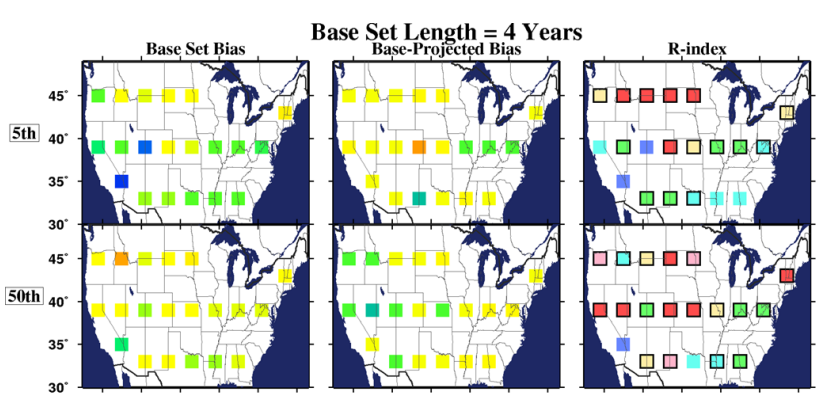

Base Set Length $=12$ Years

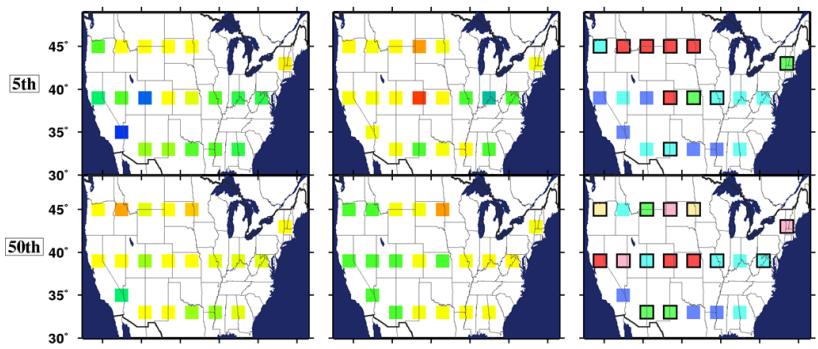

Base Set Length $=20$ Years

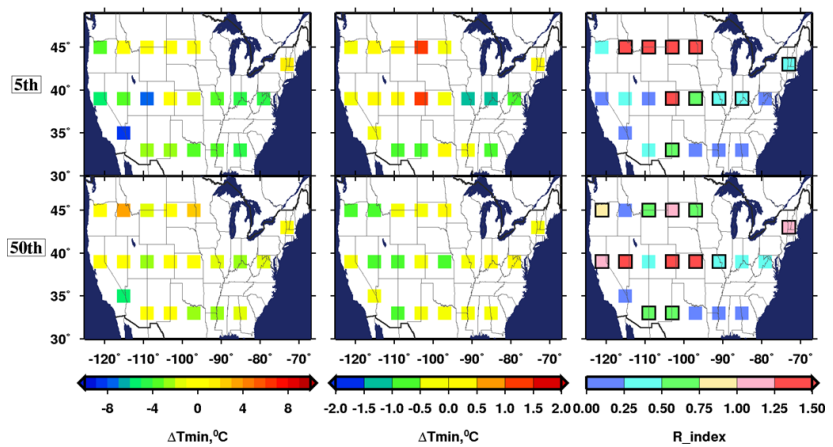

Fig. 4. Same as Fig. 3 but for DJF minimum daily temperature.
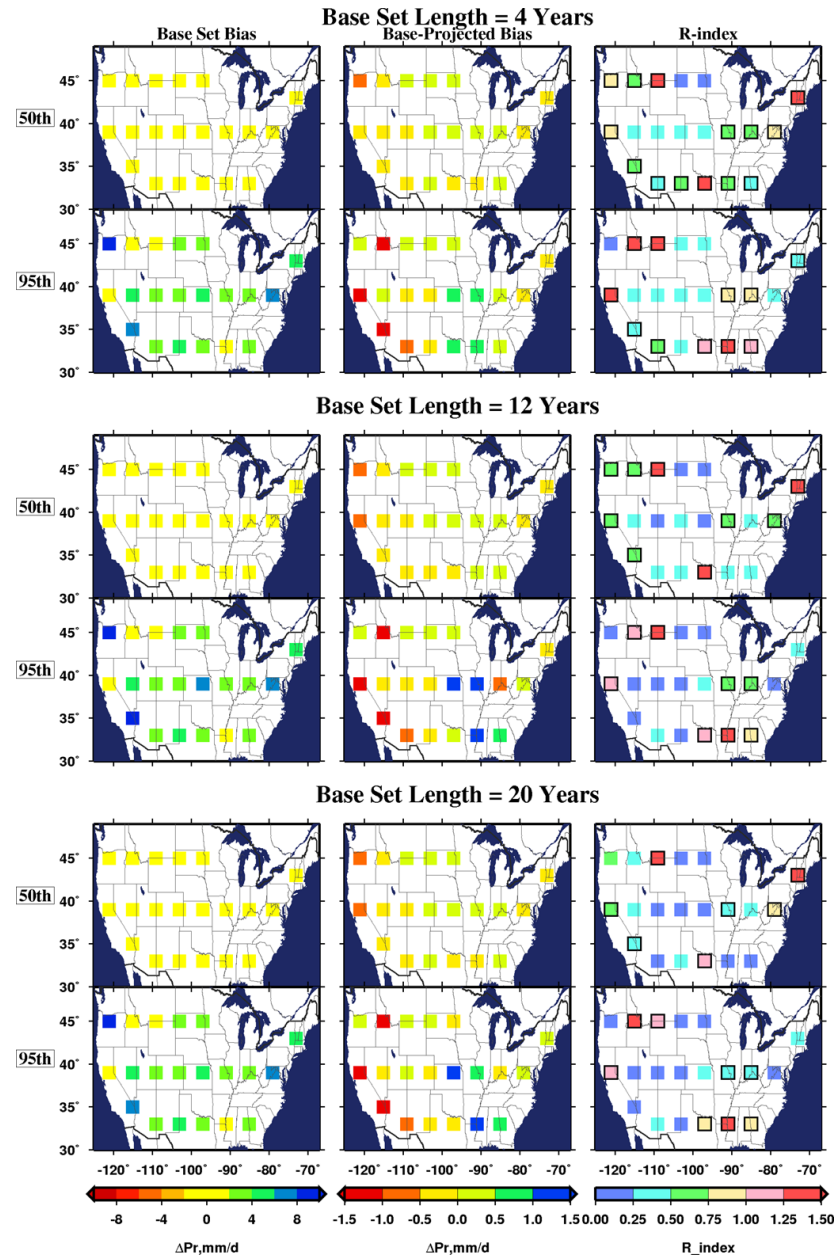

Fig. 5. Same as Fig. 3, for DJF precipitation. 
Table 2 summarizes the right columns in Figs. 3, 4, and 5 as well as the results for the other three GCMs included in this study, to assess whether some of the same patterns observed for the GFDL model are shared across the four GCMs. Table 2 shows the pattern of larger base sets providing fewer occurrences of $R>1$. This is more evident between $4 \mathrm{yr}$ and $12 \mathrm{yr}$ base sets; between 12 and $20 \mathrm{yr}$ sets the results are broadly similar. However, in many cases both median and extreme values show comparable numbers of $R>1$ occurrences at all base set sizes, with the exceptions in only a few cases (e.g., GFDL median Tmax and Tmin, and PCM and CCSM median Pr). This shows that for Tmax and Pr, in the mean, bias correction would be successful in most cases using base set sizes of only 4 randomly selected years. The single case where bias correction for more than half of the cells would fail, ultimately worsening the bias, is CCSM extreme Tmin, where 11 grid cells show $R>1$ on average. For this case, even a $20 \mathrm{yr}$ base set size does not alleviate the problem. This suggests that if the bias cannot be characterized with a few years of daily data, it may lack adequate time invariance to be amenable to this form of bias correction with any number of years constituting a base set. It is interesting that this same model has the fewest number of occurrences of $R>1$ for median daily Tmin, and demonstrates successful bias correction even with a base set of $4 \mathrm{yr}$. Thus, different processes are likely responsible for the CCSM model biases in mean and extreme daily Tmin values.

The above discussion focused on grid cells where the mean $R$ index exceeded one, in which case on average the bias correction degrades the skill. To examine a more stringent standard, Table 2 also summarizes the number of grid cells in each case where the 95th percentile $R$ values for each GCM, variable, and base set size, exceeds 1 . This approximates the number of cells (outlined in Figs. 3-5) where a 95\% confidence that $R<1$ cannot be claimed. Of the 20 grid cells analyzed in this study, as many as 18 show the $R<1$ hypothesis being rejected (CCSM extreme Tmin and GFDL median Tmin) and in other cases as few as 3 occurrences (CNRM median Tmax, CCSM extreme Tmax). While bias correction has a positive effect in the mean, the value of $R$ being below one with a high confidence (95\%) is not strongly supported, especially for Tmin and Pr.

A final observation in Table 2 of the mean number of occurrences of $R>1$ is that the GCM showing the fewest number of cases varies for different variables, base set sizes, and whether median or extreme statistics are considered. Since the relative rank among GCMs is not consistent across variables, it can be concluded that among the models used in this study no GCM can be broadly characterized as producing output that is more likely to benefit from statistical bias correction than any other GCM. However, in the case where a specific variable is of interest, some GCMs can clearly outperform others. For example, for maximum temperatures the CNRM model demonstrates more time invariance in biases than the other GCMs. Thus, the apparent time invariance of

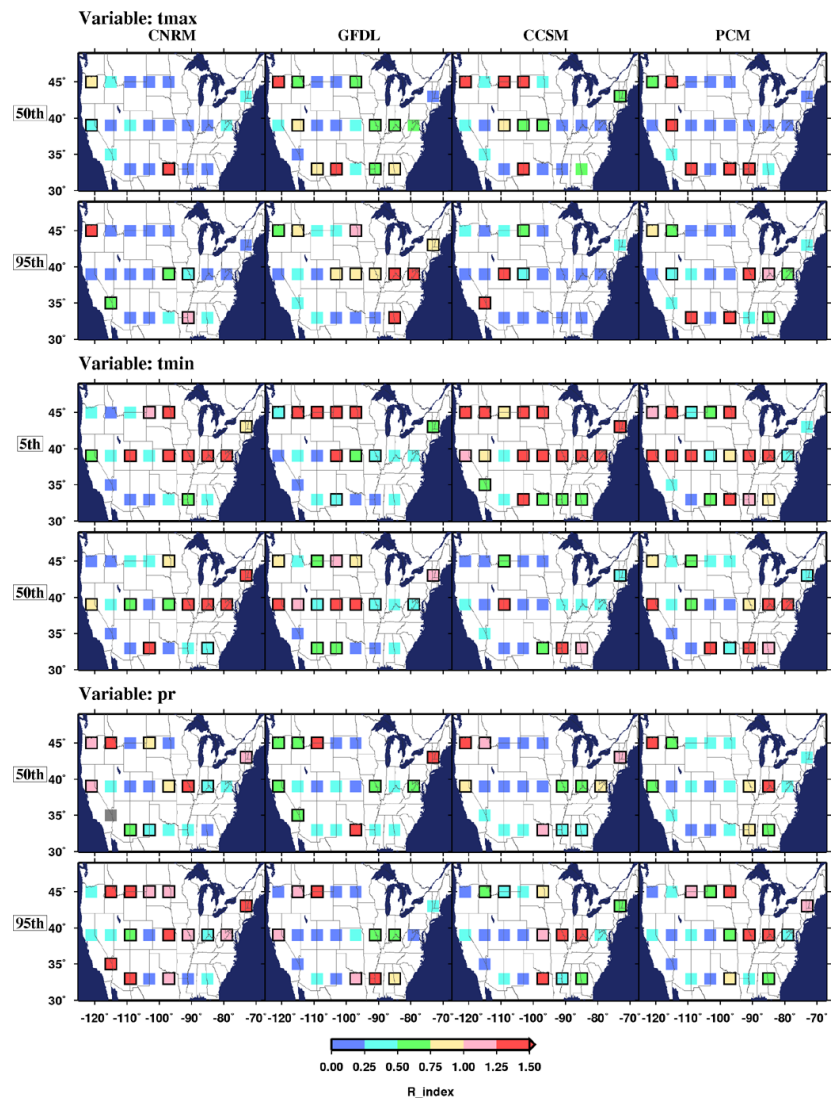

Fig. 6. $R$ values for a $12 \mathrm{yr}$ base set and a $10 \mathrm{yr}$ projected set for Tmax, Tmin, and Pr for the 4 GCMs included in this study. As with Figs. 3-5, grid cells with dark outlines indicate where $R$ values are not consistently less than 1 at $95 \%$ confidence.

biases for a specific variable and spatial domain of interest may be considered as a criterion for GCM selection when constructing ensembles, though a more comprehensive evaluation of the effectiveness of this is reserved for future research.

To illustrate some of the results in Table 2, Fig. 6 shows the mean $R$ values at all grid cells for a base set size of $12 \mathrm{yr}$ and a projected set size of $10 \mathrm{yr}$. The most important feature to note is that in most cases the grid cells where average $R>1$ are not the same for the different GCMs. The exceptions to this, where more than two of the four GCMs show $R>1$, are the 5 th percentile of minimum temperature (cells $3,12,15,17$ ), the median precipitation (cells 1,20) and the 95 th percentile precipitation (cells 6,15 , and 14). Thus, different GCMs in general exhibit time-varying biases at different locations. This suggests that by relying on an ensemble of GCMs, a quantile mapping bias correction will be more likely on average to have a beneficial effect in removing biases.

While the above assesses the time invariance of GCM biases for random sets of years, it is standard practice in statistical bias correction to use sets of consecutive years 


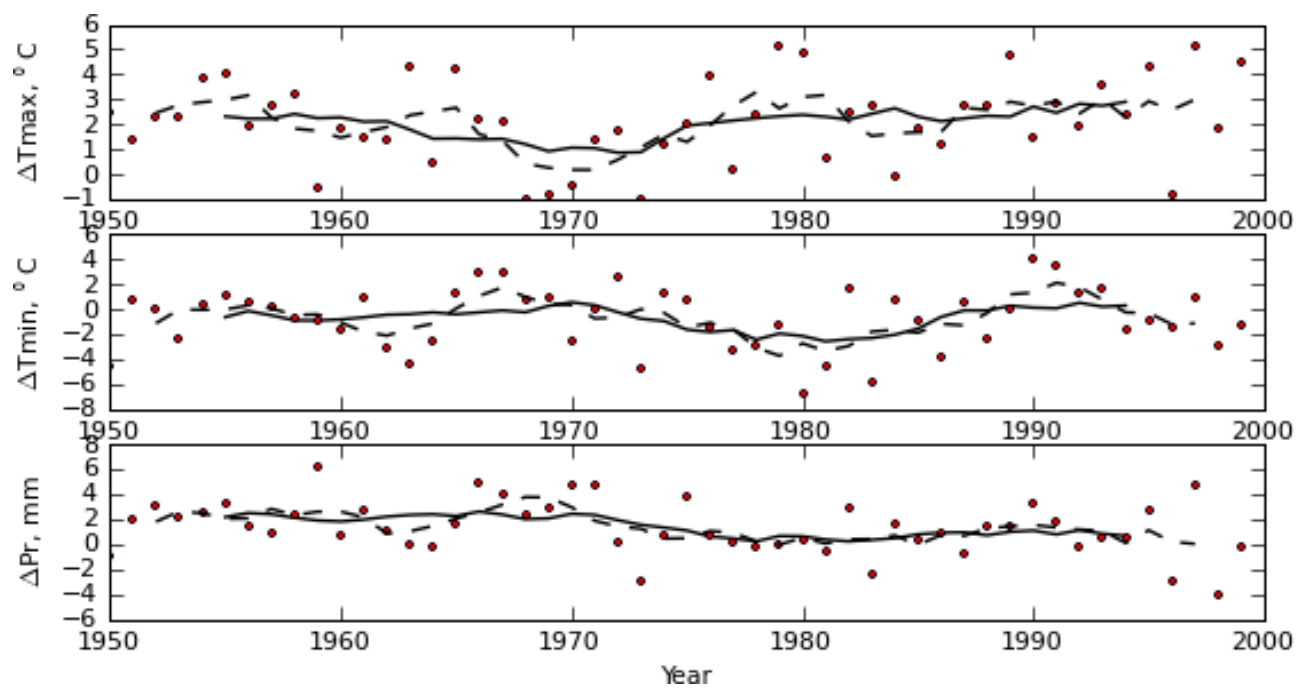

Fig. 7. Biases in seasonal statistics of daily Tmax, Tmin, and Pr based on the GFDL model from 1950-1999 at grid cell 2 (see Fig. 1). Points are biases in the median for the seasonal statistic for each year, dashed line is a $5 \mathrm{yr}$ running mean, and the solid line is an $11 \mathrm{yr}$ mean.

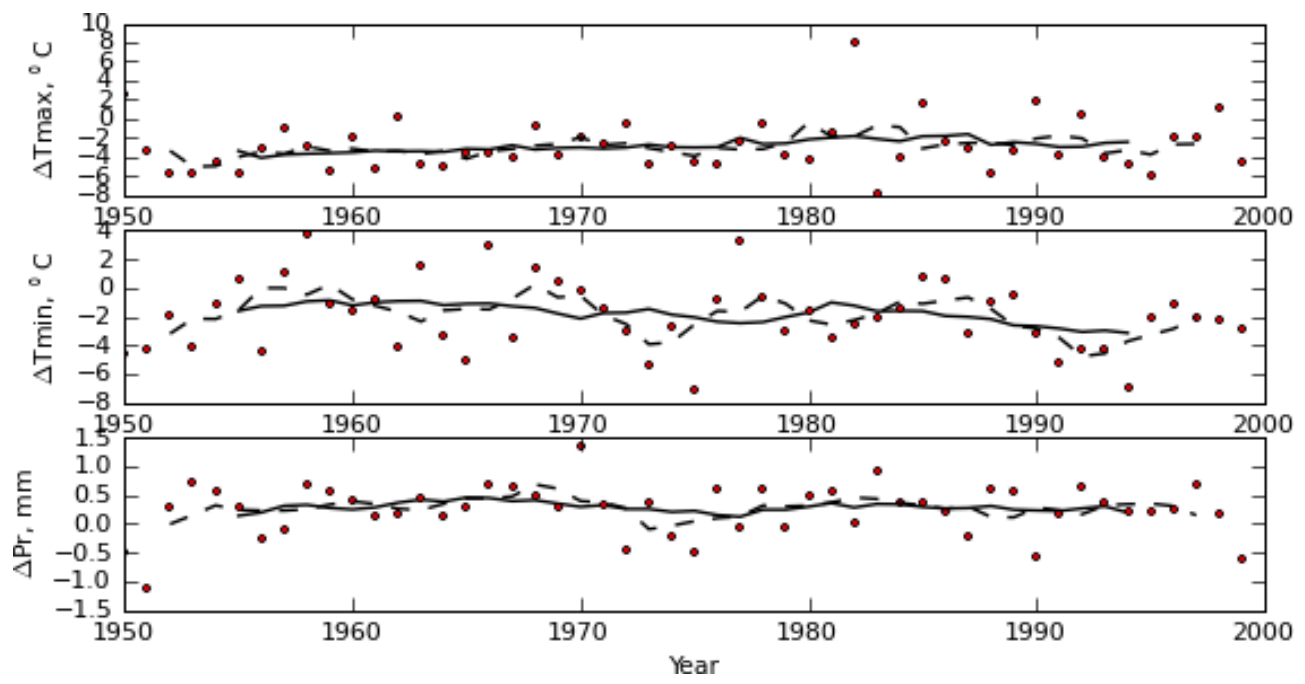

Fig. 8. Same as Fig. 7, for cell 17 (see Fig. 1).

for both the base and projected sets. With long-term persistence due to oceanic teleconnections producing decadalscale variations in climate (e.g., Cayan et al., 1998), and GCMs showing improving capability to simulate similar variability (AchutaRao and Sperber, 2006), biases would be likely to show similar low frequency variability since there would not be temporal correspondence between observations and GCM simulated low frequency variations. Figures 7 and 8 show two examples of this phenomenon using the GFDL model at two locations (other models show similar behavior). It should be emphasized that because of the lack of temporal correspondence, the biases in any one year cannot be used to evaluate the GCM performance; Figs. 7 and 8 are shown only to demonstrate the low frequency variability evident in the biases. These two locations correspond to cells 2 and 17 (see Fig. 1), being roughly located over northern California and the Ohio River valley, respectively. While the smoothed lines in Figs. 7 and 8 are continuous through the record, only the seasonal statistics are presented, so for example, there is one value of JJA Tmax for each year. While the $50 \mathrm{yr}$ period for which data were available for this study is inadequate for a robust statistical analysis of bias stability using samples of independent consecutive periods, these figures suggest that using a shorter period of $5 \mathrm{yr}$ or fewer could produce GCM biases that are more time dependent. However, a series length of $11 \mathrm{yr}$ appears to remove most of the effects of the low frequency oscillations, though some small effects do remain for temperature for the West Coast site. This could be due to the teleconnections between the Pacific Decadal Oscillation, which exhibits multidecadal persistence (Mantua 

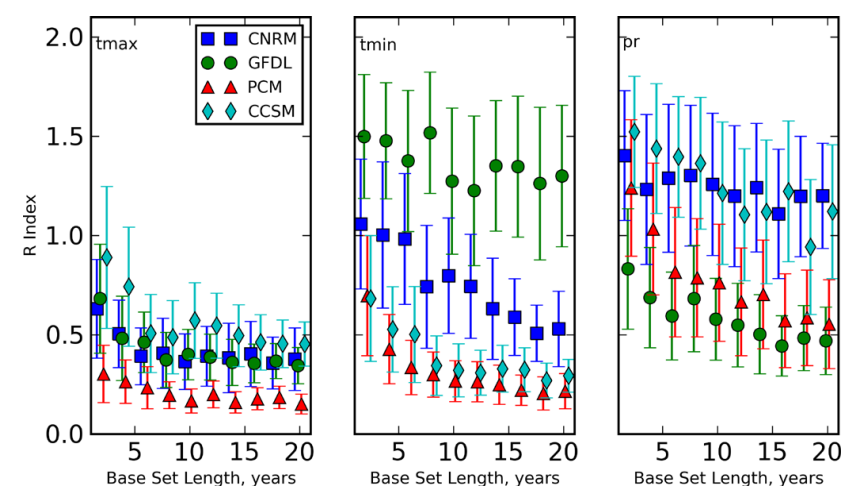

Fig. 9. For cell number 2 (see Fig. 1), $R$ index values for base set sizes from 2 to $20 \mathrm{yr}$. Points are for the mean $R$ value for the median values of the variables; the bar indicates one standard deviation centered around the point.

and Hare, 2002), and western US climate (e.g., Hidalgo and Dracup, 2003). The presence of low frequency oscillations will vary for different locations and variables. While, as explained above, a time series analysis at each grid cell is not performed as part of this study, the base set size used for statistical bias correction for any region should consider the presence and frequency of regionally-important oscillations.

The variation in the base set size needed to characterize the systematic bias at different locations is further complicated by the variation in the ability of GCMs to simulate certain oscillations and their teleconnections to regional precipitation and temperature anomalies. For the same two grid cells shown in Figs. 7 and 8, the variation in $R$ index values for base set sizes from 2 to $20 \mathrm{yr}$ is shown in Figs. 9 and 10. At both of these points bias in the median value for daily Tmax can be removed effectively, with $R$ index values reaching a low plateau with base set sizes with fewer than $10 \mathrm{yr}$ of data. The variability among GCMs is much greater for Tmin, with GFDL displaying the greatest $R$ values, which remain above 1.0 even with a $20 \mathrm{yr}$ base set size for cell 2. By contrast, GFDL performs best of all the GCMs at cell 17, with low $R$ index values achieved at $5-10 \mathrm{yr}$ of base set size. Similarly, for precipitation there is a stark contrast between the GCM that shows the least ability to have its errors successfully removed by bias correction at the two locations. If the ability to apply bias correction successfully is to be considered as a criterion for GCM selection for a regional study, Figs. 9 and 10 demonstrate that the selection would be highly dependent on the variable and location of interest.

Recognizing that the $20 \mathrm{yr}$ base set size is large relative to the size of the pool from which values are selected, this raises a concern of the degree to which the limited number of years included in this study may be affecting the results illustrated in Figs. 9 and 10, especially regarding the limited benefit of using base sets larger than about $12 \mathrm{yr}$ in quantile mapping bias correction of daily data. While extended gridded daily observational data sets for the domain are still
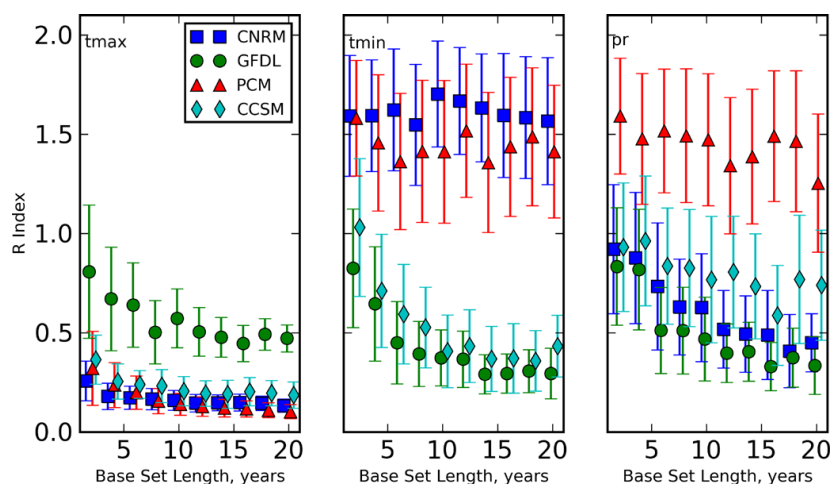

Fig. 10. Same as Fig. 9, but for cell 17.

in production (Livneh et al., 2013), we obtained the data for the regions included in Figs. 9 and 10. These extended data were produced in a manner generally consistent with the original base data but includes observed data beginning in 1915, albeit with sparser station density underlying the gridded data for the earliest periods. For the GCMs included in the study, two of them (GFDL, PCM) had daily historical precipitation, maximum and minimum temperature data archived for 1915-1999, which we used as our extended period of analysis. We aggregated the gridded observed precipitation, maximum and minimum temperature data to the same 2-degree spatial resolution for the two GCM-scale grid cells featured in Figs. 9 and 10 and repeated the analysis, with results shown in Figs. 11 and 12.

Figure 11 shows similar results to Fig. 9 for Tmax. The $R$ index values for Tmin and Pr are similar to Fig. 9 for the GFDL model, but are larger for PCM, showing greater variability in bias with time for PCM for the extended period analysis. However, base set sizes above about $12 \mathrm{yr}$, as with Fig. 9, appear to provide limited additional benefit in characterizing bias. Figure 12 is very similar to Fig. 10 for both GCMs and all 3 variables, both in the magnitude of the $R$ values and the rate of decline in mean $R$ value as the base set size increases. While limited in extent, this comparison between time invariance of biases using a shorter and an extended base data set suggests that the analysis is relatively robust with regard to the finding that base set sizes longer than about $12 \mathrm{yr}$ provide small marginal benefit.

\section{Summary and conclusions}

We examined simulated daily precipitation and maximum and minimum temperatures from four GCMs over the conterminous United States, and compared the simulated values to daily observations aggregated to the GCM scale. Our motivation was to examine some of the basic assumptions involved in statistical bias correction techniques used to treat the GCM output in climate change impact studies. The techniques assume that the biases can be represented as the difference 

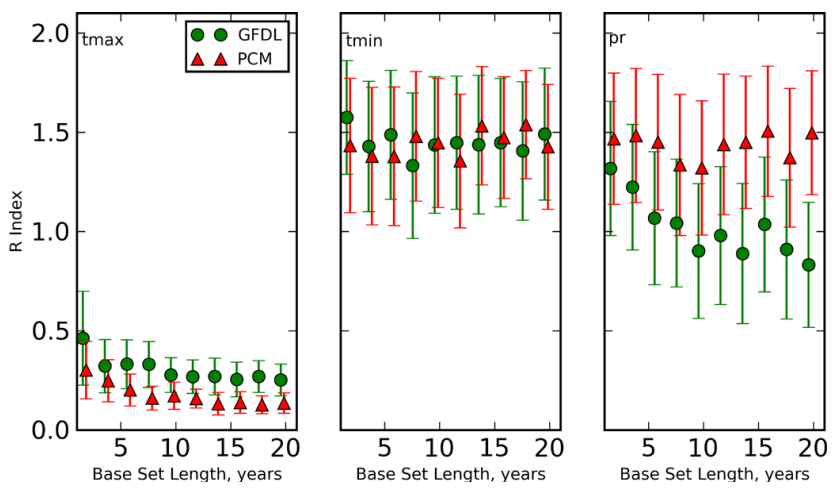

Fig. 11. Similar to Fig. 9, but using an extended observational base period and GCM output.

between observations and GCM simulated values, and that these biases will remain the same into the future.

We performed Monte Carlo simulations, randomly selecting years from the historic record to represent the base set, which varied in size, and a non-overlapping $10 \mathrm{yr}$ projected set (drawn from a different set of years in the historical period). The biases for each Monte Carlo simulation were compiled for a median value of each variable, and one extreme value: the $95 \%$ (non-exceedence) precipitation, $95 \%$ Tmax, and $5 \%$ Tmin. For each Monte Carlo simulation, an indicator, here termed the $R$ index, was computed. The $R$ index represents the change in bias between the base and projected sets, and normalizes this by the mean bias. The mean and approximate $95 \%$ value of the $R$ index were calculated to assess the likelihood that bias correction could be successfully applied at each grid cell for each variable.

Our principal findings are:

1. In most locations, on average the GCM bias is statistically the same between two different sets of years. This means a quantile-mapping bias correction on average can have a positive effect in removing a portion of the GCM bias.

2. For characterizing daily GCM output, our findings indicate variability in the number of years required to characterize bias for different GCMs and variables. On average a base set with as few as 4 randomly-selected years is often adequate to characterize the biases in daily GCM precipitation and temperature, at both median and extreme values. A base set of $12 \mathrm{yr}$ provided improvement in the number of grid cells where high confidence in successful bias correction could be claimed.

3. For most variables and GCMs the characterization of the bias shows little improvement with base set sizes larger than about $10 \mathrm{yr}$. In a few cases the variability in bias between different sets of years is high enough that even a $20 \mathrm{yr}$ base set size cannot provide the necessary
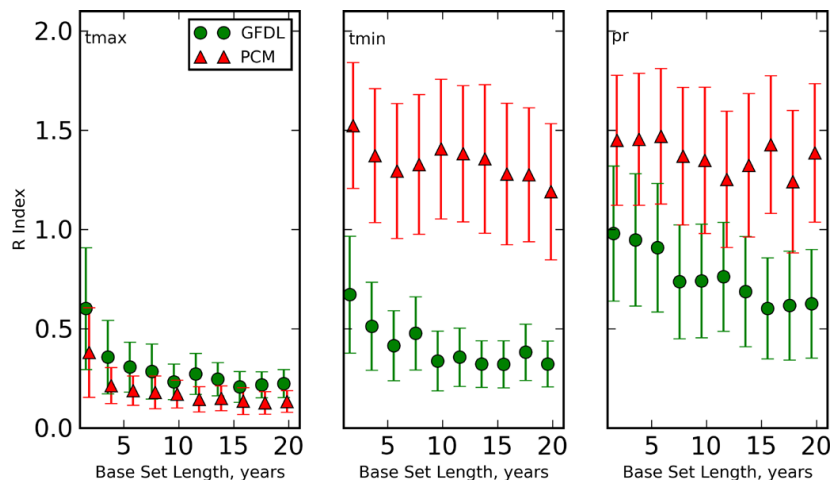

Fig. 12. Similar to Fig. 10, but using an extended observational base period and GCM output.

time invariance between sets of years to allow successful bias correction with quantile mapping.

4. When considering consecutive rather than randomly selected years, the GCM biases exhibit low frequency variability similar to observations, and the selected base period must be long enough to remove their effect.

5. At any location, the biases in the base and projected sets of years for a particular variable were fairly consistent for any given GCM, regardless of base set size. This reflects that there are geographical manifestations to some of the GCM shortcomings that cause bias, such as the inadequate topography represented at coarse resolutions. There are differences between the magnitude of biases at the mean and extreme values (especially for precipitation), but the differences in the biases between the base and projected sets of years are comparable for both mean and extreme values.

These findings can be interpreted as cautiously encouraging to those who use quantile mapping to bias correct GCM output to estimate climate change impacts. Our results suggest that a statistical removal of the GCM bias, characterized by comparing GCM simulations for a historic period to observations, is on average justified and robust. There were rare cases where at one location (for a specific variable and statistic) an individual GCM might on average have biases that vary in time to the point where the bias correction would actually increase bias. However, other GCMs did not generally exhibit this characteristic at the same point. This suggests that as long as an ensemble of many GCMs is used, on average the bias correction will be beneficial. Where only one or a few GCMs are used for a climate impact study, it may be advisable to investigate the time dependence of GCM biases before using the bias corrected output for climate impacts analysis. In addition, the time invariance of biases for variables and locations of interest could potentially be used as a means to favor using certain GCMs for regional studies. 
Since this study only examined the stationarity in time of daily GCM biases, those at longer timescales are not explicitly addressed. However, Maurer et al. (2010) show that a quantile mapping bias correction of daily data can result in the removal of most biases in monthly GCM output. In another study, Coats et al. (2013), with details in Coats et al. (2010), found that quantile mapping of precipitation at the daily timescale resulted in monthly and annual distributions in remarkably good agreement with observations. This suggests that by bias correcting at a daily scale the biases at longer timescales may also be accommodated.

Future work will extend this analysis for the new model formulations producing climate simulations for the IPCC Fifth Assessment for a larger ensemble and a longer observational period. This will allow the testing of model simulations for a longer observational period including the most recent decade, when large-scale warming has accelerated, providing more extreme cases for the above tests. Biases and their time invariance will also be investigated at scales finer than the $2^{\circ}$ resolution used in this study, reflecting both the finer resolution of the new GCMs and the latest implementations of quantile mapping bias correction at finer scales. In addition, new daily observational data sets of close to $100 \mathrm{yr}$ in length (e.g., Casola et al., 2009) will allow more intensive investigation of GCM biases by facilitating compositing on different conditions such as regional climate or oscillation phase.

Acknowledgements. This research was supported in part by the California Energy Commission Public Interest Energy Research (PIER) Program. During the development of the majority of this work, T. Das was working as a scientist at Scripps Institution of Oceanography. The CALFED Bay-Delta program post-doctoral fellowship provided partial support for T. Das. The authors are grateful for the thoughtful and constructive comments of the reviewers, whose feedback substantially improved our methods and interpretation of results.

Edited by: L. Samaniego

\section{References}

Abatzoglou, J. T. and Brown, T. J.: A comparison of statistical downscaling methods suited for wildfire applications, Int. J. Climatol., 32, 772-780, doi:10.1002/joc.2312, 2012.

AchutaRao, K. M. and Sperber, K. R.: ENSO Simulation in Coupled Ocean-Atmosphere Models: Are the Current Models Better?, Clim. Dynam., 27, 1-15, doi:10.1007/s00382-006-0119-7, 2006.

Ballester, J., Giorgi, F., and Rodo, X.: Changes in European temperature extremes can be predicted from changes in PDF central statistics, Climatic Change, 98, 277-284, doi:10.1007/s10584009-9758-0, 2010.

Boé, J., Terray, L., Habets, F., and Martin, E.: Statistical and dynamical downscaling of the Seine basin climate for hydro-meteorological studies, Int. J. Climatol., 27, 1643-1655, doi:10.1002/joc.1602, 2007.

Bürger, G., Murdock, T. Q., Werner, A. T., Sobie, S. R., and Cannon, A. J.: Downscaling Extremes - An Intercomparison of Multiple Statistical Methods for Present Climate, J. Climate, 25, 43664388, doi:10.1175/jcli-d-11-00408.1, 2012.

Buser, C. M., Kunsch, H. R., Luthi, D., Wild, M., and Schar, C.: Bayesian multi-model projection of climate: bias assumptions and interannual variability, Clim. Dynam., 33, 849-868, doi:10.1007/s00382-009-0588-6, 2009.

Carter, T. R., Jones, R. N., Lu, X., Bhadwal, S., Conde, C., Mearns, L. O., O'Neill, B. C., Rounsevell, M. D. A., and Zurek, M. B.: New Assessment Methods and the Characterisation of Future Conditions. Climate Change 2007: Impacts, Adaptation and Vulnerability. Contribution of Working Group II to the Fourth Assessment Report of the Intergovernmental Panel on Climate Change, in, edited by: Parry, M. L., Canziani, O. F., Palutikof, J. P., van der Linden, P. J., and Hanson, C. E., Cambridge University Press, Cambridge, UK, 133-171, 2007.

Casola, J. H., Cuo, L., Livneh, B., Lettenmaier, D. P., Stoelinga, M. T., Mote, P. W., and Wallace, J. M.: Assessing the Impacts of Global Warming on Snowpack in the Washington Cascades*, J. Climate, 22, 2758-2772, doi:10.1175/2008jcli2612.1, 2009.

Cayan, D. R., Dettinger, M. D., Diaz, H. F., and Graham, N. E.: Decadal Variability of Precipitation over Western North America, J. Climate, 11, 3148-3166, doi:10.1175/15200442(1998)011<3148:DVOPOW>2.0.CO;2, 1998.

Chen, C., Haerter, J. O., Hagemann, S., and Piani, C.: On the contribution of statistical bias correction to the uncertainty in the projected hydrological cycle, Geophys. Res. Lett., 38, L20403, doi:10.1029/2011g1049318, 2011.

Christensen, J. H., Hewitson, B., Busuioc, A., Chen, A., Gao, X., Held, I., Jones, R., Kolli, R. K., Kwon, W.-T., Laprise, R., Magaña Rueda, V., Mearns, L., Menéndez, C. G., Räisänen, J., Rinke, A., Sarr, A., and Whetton, P.: Regional climate projections, in: Climate Change 2007: The Physical Science Basis. Contribution of Working Group I to the Fourth Assessment Report of the Intergovernmental Panel on Climate Change, edited by: Solomon, S., Qin, D., Manning, M., Chen, Z., Marquis, M., Averyt, K. B., Tignor, M., and Miller, H. L., Cambridge University Press, Cambridge, United Kingdom and New York, NY, USA, 2007.

Christensen, J. H., Boberg, F., Christensen, O. B., and LucasPicher, P.: On the need for bias correction of regional climate change projections of temperature and precipitation, Geophys. Res. Lett., 35, L20709, doi:10.1029/2008g1035694, 2008.

Coats, R., Reuter, J., Dettinger, M., Riverson, J., Sahoo, G., Schladow, G., Wolfe, B., and Costa-Cabral, M.: The effects of climate change on Lake Tahoe in the 21st century: Meteorology, hydrology, loading and lake response, Pacific Southwest Research Station, Tahoe Environmental Science Center, Incline Village NV, USA, 208, 2010.

Coats, R., Costa-Cabral, M., Riverson, J., Reuter, J., Sahoo, G., Schladow, G., and Wolfe, B.: Projected 21 st century trends in hydroclimatology of the Tahoe basin, Climatic Change, 116, 5169, doi:10.1007/s10584-012-0425-5, 2013.

Daly, C., Neilson, R. P., and Phillips, D. L.: A statisticaltopographic model for mapping climatological precipitation over mountainous terrain, J. Appl. Meteorol., 33, 140-158, 1994. 
Delworth, T. L., Broccoli, A. J., Rosati, A., Stouffer, R. J., Balaji, V., Beesley, J. A., Cooke, W. F., Dixon, K. W., Dunne, J., Dunne, K. A., Durachta, J. W., Findell, K. L., Ginoux, P., Gnanadesikan, A., Gordon, C. T., Griffies, S. M., Gudgel, R., Harrison, M. J., Held, I. M., Hemler, R. S., Horowitz, L. W., Klein, S. A., Knutson, T. R., Kushner, P. J., Langenhorst, A. R., Lee, H.-C., Lin, S.-J., Lu, J., Malyshev, S. L., Milly, P. C. D., Ramaswamy, V., Russell, J., Schwarzkopf, M. D., Shevliakova, E., Sirutis, J. J., Spelman, M. J., Stern, W. F., Winton, M., Wittenberg, A. T., Wyman, B., Zeng, F., and Zhang, R.: GFDL's CM2 global coupled climate models - Part 1: Formulation and simulation characteristics, J. Climate, 19, 643-674, 2006.

Ehret, U., Zehe, E., Wulfmeyer, V., Warrach-Sagi, K., and Liebert, J.: HESS Opinions "Should we apply bias correction to global and regional climate model data?", Hydrol. Earth Syst. Sci., 16, 3391-3404, doi:10.5194/hess-16-3391-2012, 2012.

Fowler, H. J., Blenkinsop, S., and Tebaldi, C.: Linking climate change modelling to impacts studies: recent advances in downscaling techniques for hydrological modelling, Int. J. Climatol., 27, 1547-1578, doi:10.1002/joc.1556, 2007.

Frich, P., Alexander, L. V., Della-Marta, P., Gleason, B., Haylock, M., Klein Tank, A. M. G., and Peterson, T. C.: Observed Coherent changes in climatic extremes during the second half of the twentieth century, Clim. Res., 19, 193-212, 2002.

Haerter, J. O., Hagemann, S., Moseley, C., and Piani, C.: Climate model bias correction and the role of timescales, Hydrol. Earth Syst. Sci., 15, 1065-1079, doi:10.5194/hess-15-10652011, 2011.

Hall, A., Qu, X., and Neelin, J. D.: Improving predictions of summer climate change in the United States, Geophys. Res. Lett., 35, L01702, doi:10.1029/2007GL032012, 2008.

Hawkins, E. and Sutton, R.: The Potential to Narrow Uncertainty in Regional Climate Predictions, B. Am. Meteorol. Soc., 90, 10951107, doi:10.1175/2009BAMS2607.1, 2009.

Hewitson, B.: Developing perturbations for climate change impact assessments, EOS T. Am. Geophys. Un., 84, 337-341, doi:10.1029/2003EO350001, 2003.

Hidalgo, H. G. and Dracup, J. A.: ENSO and PDO Effects on Hydroclimatic Variations of the Upper Colorado River Basin, J. Hydrometeorol., 4, 5-23, doi:10.1175/15257541(2003)004<0005:eapeoh>2.0.co;2, 2003.

Ines, A. V. M. and Hansen, J. W.: Bias correction of daily GCM rainfall for crop simulation studies, Agr. Forest Meteorol., 138, 44-53, 2006.

Karl, T. R., Melillo, J. M., and Peterson, D. H.: Global climate change impacts in the United States, Cambridge University Press, New York, 192 pp., 2009.

Kiehl, J. T., Hack, J. J., Bonan, G. B., Boville, B. B., Williamson, D. L., and Rasch, P. J.: The National Center for Atmospheric Research Community Climate Model: CCM3, J. Climate, 11, 11311149, 1998.

Klein, S. A., Jiang, X., Boyle, J., Malyshev, S., and Xie, S.: Diagnosis of the summertime warm and dry bias over the U.S. Southern Great Plains in the GFDL climate model using a weather forecasting approach, Geophys. Res. Lett., 33, L18805, doi:10.1029/2006g1027567, 2006.

Knutti, R., Allen, M. R., Friedlingstein, P., Gregory, J. M., Hegerl, G. C., Meehl, G. A., Meinshausen, M., Murphy, J. M., Plattner, G. K., Raper, S. C. B., Stocker, T. F., Stott, P. A., Teng, H., and
Wigley, T. M. L.: A review of uncertainties in global temperature projections over the twenty-first century, J. Climate, 21, 26512663, doi:10.1175/2007jcli2119.1, 2008.

Lafon, T., Dadson, S., Buys, G., and Prudhomme, C.: Bias correction of daily precipitation simulated by a regional climate model: a comparison of methods, Int. J. Climatol., 33, 13671381, doi:10.1002/joc.3518, 2012.

Li, H., Sheffield, J., and Wood, E. F.: Bias correction of monthly precipitation and temperature fields from Intergovernmental Panel on Climate Change AR4 models using equidistant quantile matching, J. Geophys. Res., 115, D10101, doi:10.1029/2009jd012882, 2010.

Livneh, B., Rosenberg, E. A., Lin, C., Nijssen, B., Mishra, V., Andreadis, K., Maurer, E. P., and Lettenmaier, D. P.: A Long-term hydrologically based dataset of land surface fluxes and states for the conterminous U.S.: Update and extensions, 25th Conference on Climate Variability and Change, 93rd American Meteorological Society Annual Meeting, Austin, TX, USA, Paper 6A.3, 2013.

Macadam, I., Pitman, A. J., Whetton, P. H., and Abramowitz, G.: Ranking climate models by performance using actual values and anomalies: Implications for climate change impact assessments, Geophys. Res. Lett., 37, L16704, doi:10.1029/2010g1043877, 2010.

Mantua, N. J. and Hare, S. R.: The Pacific Decadal Oscillation, J. Oceanogr., 58, 35-44, 2002.

Maraun, D.: Nonstationarities of regional climate model biases in European seasonal mean temperature and precipitation sums, Geophys. Res. Lett., 39, L06706, doi:10.1029/2012gl051210, 2012.

Maraun, D., Wetterhall, F., Ireson, A. M., Chandler, R. E., Kendon, E. J., Widmann, M., Brienen, S., Rust, H. W., Sauter, T., Themeß1, M., Venema, V. K. C., Chun, K. P., Goodess, C. M., Jones, R. G., Onof, C., Vrac, M., and Thiele-Eich, I.: Precipitation downscaling under climate change: Recent developments to bridge the gap between dynamical models and the end user, Rev. Geophys., 48, RG3003, doi:10.1029/2009rg000314, 2010.

Masson, D. and Knutti, R.: Spatial-Scale Dependence of Climate Model Performance in the CMIP3 Ensemble, J. Climate, 24, 2680-2692, doi:10.1175/2011jcli3513.1, 2011.

Maurer, E. P., Wood, A. W., Adam, J. C., Lettenmaier, D. P., and Nijssen, B.: A long-term hydrologically-based data set of land surface fluxes and states for the conterminous United States, J. Climate, 15, 3237-3251, 2002.

Maurer, E. P., Hidalgo, H. G., Das, T., Dettinger, M. D., and Cayan, D. R.: The utility of daily large-scale climate data in the assessment of climate change impacts on daily streamflow in California, Hydrol. Earth Syst. Sci., 14, 1125-1138, doi:10.5194/hess14-1125-2010, 2010.

Meehl, G. A., Covey, C., Delworth, T., Latif, M., McAvaney, B., Mitchell, J. F. B., Stouffer, R. J., and Taylor, K. E.: The WCRP CMIP3 multimodel dataset: A new era in climate change research, B. Am. Meteorol. Soc., 88, 1383-1394, 2007.

Panofsky, H. A. and Brier, G. W.: Some Applications of Statistics to Meteorology, The Pennsylvania State University, University Park, PA, USA, 224 pp., 1968.

Piani, C., Haerter, J., and Coppola, E.: Statistical bias correction for daily precipitation in regional climate models over Europe, Theor. Appl. Climatol., 99, 187-192, doi:10.1007/s00704-009- 
0134-9, 2010.

Pierce, D. W., Das, T., Cayan, D., Maurer, E. P., Bao, Y., Kanamitsu, M., Yoshimura, K., Snyder, M. A., Sloan, L. C., Franco, G., and Tyree, M.: Probabilistic estimates of future changes in California temperature and precipitation using statistical and dynamical downscaling, Clim. Dynam., 40, 839-856, doi:10.1007/s00382012-1337-9, 2013.

Pyke, C. B.: Some meteorological aspects of the seasonal distribution of precipitation in the western United States and Baja California, University of California Water Resources Center Contribution 139, Berkeley, CA, 205, 1972.

Randall, D. A., Wood, R. A., Bony, S., Colman, R., Fichefet, T., Fyfe, J., Kattsov, V., Pitman, A., Shukla, J., Srinivasan, J., Sumi, A., Stouffer, R. J., and Taylor, K. E.: Climate models and their evaluation, in: Climate Change 2007: The Physical Science Basis. Contribution of Working Group I to the Fourth Assessment Report of the Intergovernmental Panel on Climate Change, edited by: Solomon, S., Qin, D., Manning, M., Chen, Z., Marquis, M., Averyt, K. B., Tignor, M., and Miller, H. L., Cambridge University Press, Cambridge, UK, 591-648, 2007.

Salas-Mélia, D., Chauvin, F., Déqué, M., Douville, H., Gueremy, J. F., Marquet, P., Planton, S., Royer, J. F., and Tyteca, S.: Description and validation of the CNRM-CM3 global coupled model, CNRM working note 103, Centre National de Recherches Météorologiques, Météo-France, Toulouse, France, 36 pp., 2005.

Sun, Y., Solomon, S., Dai, A., and Portmann, R. W.: How Often Does It Rain?, J. Climate, 19, 916-934, doi:10.1175/jcli3672.1, 2006.

Tebaldi, C., Hayhoe, K., Arblaster, J. M., and Meehl, G. A.: An intercomparison of model-simulated historical and future changes in extreme events, Climatic Change, 79, 185-211, doi:10.1007/s10584-006-9051-4, 2006.
Themeß1, M., Gobiet, A., and Heinrich, G.: Empirical-statistical downscaling and error correction of regional climate models and its impact on the climate change signal, Climatic Change, 112, 449-468, doi:10.1007/s10584-011-0224-4, 2012.

Thrasher, B., Maurer, E. P., McKellar, C., and Duffy, P. B.: Technical Note: Bias correcting climate model simulated daily temperature extremes with quantile mapping, Hydrol. Earth Syst. Sci., 16, 3309-3314, doi:10.5194/hess-16-3309-2012, 2012.

Tryhorn, L. and DeGaetano, A.: A comparison of techniques for downscaling extreme precipitation over the Northeastern United States, Int. J. Climatol., 31, 1975-1989, doi:10.1002/joc.2208, 2011.

Vicuna, S., Dracup, J. A., Lund, J. R., Dale, L. L., and Maurer, E. P.: Basin-scale water system operations with uncertain future climate conditions: Methodology and case studies, Water Resour. Res., 46, W04505, doi:10.1029/2009WR007838, 2010.

Washington, W. M., Weatherly, J. W., Meehl, G. A., Semtner, A. J., Bettge, T. W., Craig, A. P., Strand, W. G., Arblaster, J., Wayland, V. B., James, R., and Zhang, Y.: Parallel climate model (PCM) control and transient simulations, Clim. Dynam., 16, 755-774, 2000.

Wehner, M.: Sources of uncertainty in the extreme value statistics of climate data, Extremes, 13, 205-217, doi:10.1007/s10687-0100105-7, 2010.

Wood, A. W., Leung, L. R., Sridhar, V., and Lettenmaier, D. P.: Hydrologic implications of dynamical and statistical approaches to downscaling climate model outputs, Climatic Change, 62, 189216, 2004.

Yevjevich, V.: Probability and Statistics in Hydrology, Water Resources Publications, Ft. Collins, CO, USA, 1972. 